Working Paper

in Economics and

Development Studies

Department of Economics

Padjadjaran University

No. 201405

\title{
Are Smarter People Better Samaritans? \\ Effect of Cognitive Abilities on Pro- Social Behaviors
}

Luis Aranda ${ }^{1}$

Martin Siyaranamual ${ }^{2}$

${ }^{1}$ Advanced School of Economics, University Ca' Foscari of Venice

${ }^{2}$ Department of Economics, Padjadjaran University

March, 2014

Center for Economics and Development Studies, Department of Economics, Padjadjaran University Jalan Cimandiri no. 6, Bandung, Indonesia.

Phone/Fax: +62-22-4204510

http://www.ceds.fe.unpad.ac.id

For more titles on this series, visit:

http://econpapers.repec.org/paper/unpwpaper/ 


\title{
Are Smarter People Better Samaritans? Effect of Cognitive Abilities on Pro-Social Behaviors
}

\author{
Luis Aranda \\ Martin Siyaranamual \\ Advanced School of Economics, University Ca' Foscari of Venice
}

March 2014

\begin{abstract}
This study investigates the link between cognitive abilities and civic engagement of older Europeans (aged 50+), using waves two and three of the SHARE dataset. An instrumental variable approach is employed in an attempt to disentangle possible endogeneity issues arising between cognition and pro-social behaviors. In so doing, cognitive abilities are instrumented with the number of books in the respondent's place of residence during childhood. The results advocate for the existence of a causal relationship running from cognition in old age to community engagement. Though contradicting standard theoretical predictions, this empirical finding is in line with mainline experimental results showing how participants with higher cognitive abilities tend to be less risk averse, and thus more willing to opt for a payoff-dominant action in a stag hunt game context more often.
\end{abstract}

Keywords: Cognitive ability; civic engagement; instrumental variables; risk aversion; we-rationality.

JEL: D03, D64, D71 


\section{Introduction}

Why are people willing to engage in pro-social activities? Much of today's economic analysis is based on the assumptions that people are both rational (in the Nash equilibrium notion) and selfish. For example, in the context of the prisoner's dilemma, stag hunt games, or in the private provision of public goods, people are assumed to be clever enough to figure out that defection and free riding are the risk-dominant strategies. However, empirical and experimental evidence seems to reject the traditional conjecture of defective behavior under the social dilemma condition. ${ }^{1}$

In general, two arguments have been used to justify people's preferences toward pro-social activities. The first argument conforms to the standard theory of rational individual choice in that it claims that people actively engage in pro-social activities for the sole reason that it makes them feel good, either because they care about what others think of them or because they feel better about themselves, but not necessarily because they care about the public benefit per se. This feeling of complacency which motivates individuals to participate in society has been referred to in the literature as the "warm-glow" effect (Andreoni, 1990; Bernheim and Rangel, 2005).

The second argument challenges the purely-selfish individual concept of standard theory by asserting that, when making choices, people not only care about their own preferences but also about the preferences of others. Several theories have been put forth along these lines, stemming from notions of altruism, reciprocity, kindness, and other-oriented or other-regarding preferences, to name a few. Of particular interest -due to their ability to account for cooperative behavior even in the presence of individual incentives to freeride- are the theories of "we-rationality" 2 proposed by Hodgson (1967) and

\footnotetext{
1 "Empirical and experimental analyses have then brought up a new series of results providing sound and robust evidence of economically relevant behaviors not motivated by self-regard. Cooperative choices registered through prisoner's dilemma experiments (even in one-shot interactions) were among the earliest 'anomalies' to be investigated" (Samuelson, 2005, p. 490).

${ }^{2}$ Several naming variations exist -e.g., team preferences, we-reasoning or we-thinking, collective or team agency, among others- though the main concept remains for the most part unchanged.
} 
Regan (1980) and later developed by Gilbert (1989), Hurley (1989), Sugden (1993, 2000, 2003), Hollis and Sugden (1993), Hollis (1998), Bacharach (2006), and Smerilli (2012). ${ }^{3}$ These theories differentiate themselves from the standard "I-thinking" by allowing groups to deliberate as agents, effectively contextualizing the individual and hence accounting for her relational nature. Individuals see themselves as members of a group or team and act accordingly, seeking an answer to the question "What should we do?". An optimal group action $A$ is composed by the individual actions $A_{i}$ of each of its members; by choosing $A_{i}$, each individual acts in the credence that the other group members will select their constituents of $A$ as well. This will produce the feasible outcome which is "most highly ranked in terms of the team's preferences" (Sugden, 2000, p. 196). Though by no means substituting individual rational choice, we-rationality theories surpass it in that they overcome the methodological individualism as the exclusive approach to human rationality.

Going beyond the relational context of decision-making, pro-social behaviors may be strongly influenced by characteristics which are intrinsic to the individual. For instance, a growing body of literature tries to improve understanding of a wide range of behaviors by conceptualizing choice as originating from cognitive functions, which are not only heterogeneous across subjects but also influenced by external factors. As a matter of fact, in experimental and psychological economics literature cognitive hierarchy is included in the model of decision making (Nagel, 1995; Costa-Gomes et al., 2001; Camerer et al., 2004). In addition, the relationships between cognition and outcomes in experimental settings (Brandstätter and Güth, 2002; Ben-Ner et al., 2004) and between cognitive ability and financial decisions (Christelis et al., 2010) have been broadly documented.

Nonetheless, detailed analyses on the relationship between cognitive abil-

\footnotetext{
${ }^{3}$ Hollis (1998) makes the following observation about cooperation even in the presence of free-riding: "Why do people who contribute to public goods fret about free-riders in some cases but not in others? There is a logic of 'enough,' I submit, which can overcome the dominance of defection, provided that a sense of membership is in play. Donors cooperate if confident that enough blood is being provided by enough members...Enough is then enough" (p. 146).
} 
ity and pro-social behaviors (considering in particular volunteering and civic engagement) are for the most part missing or inconclusive. Potentially, however, this relationship may represent a significant factor from both theoretical and practical perspectives. For researchers, for instance, understanding the relationship between cognitive ability and pro-social behaviors may shed light on the underlying mechanisms of cooperation among individuals. Additionally, it may help policy makers better devise inclusive policies which enhance participation and community engagement for the advancement of society as a whole.

Civic engagement has become a particularly relevant issue when considering the well-being of older individuals, either on or approaching retirement. Post-retirement engagement and socialization have been consistently shown to reduce both physical and mental decline in old age (Fratiglioni et al., 2004a,b; Berkman et al., 2000; Zunzunegui et al., 2003; Everard et al., 2000), providing for a more socially and economically active society. However, to our knowledge empirical evidence showing a link from cognition to civic participation is still lacking. The aim and novelty of this paper is thus exploring the causal link that cognitive abilities have on pro-social engagement in old age from an empirical perspective.

Our results, using data from the Survey of Health, Aging and Retirement in Europe (SHARE), indicate higher cognitive abilities as seemingly causal determinants of pro-social behaviors. In particular, retrospective information on the number of books at home when the respondent was ten years old as well as the respondent's height is used to instrument cognition in older age $(50+)$ and exogenously estimate its impact on civic engagement. As a result, individuals in this age group with higher cognitive abilities are found to be significantly more willing to engage in pro-social activities.

This paper is structured as follows. The next section reviews traditional economic findings which predict uncooperative behavior as the optimal strategy in public goods games and sets the theoretical bases that justify the present work. Section 3 gives an overview of the data, variables and empirical methodology, while the results and a series of robustness checks are presented in Section 4. Section 5 concludes. 


\section{Theoretical Background}

The present study builds upon two strands of economic literature. First, the literature relating uncooperative behaviors in a social dilemma situation to a higher degree of risk aversion. Second, the theoretical studies linking risk aversion to cognitive ability.

Investing one's own resources in civic activities without knowing whether other community members are willing to participate can be viewed as a risky decision. In this sense, risk aversion might influence people's behaviors toward the production of public goods. In the book A Discourse on Inequality, Jean-Jacques Rousseau illustrated this situation in his influential stag hunt parable, which serves as the theoretical starting point of the present paper.

Assume that two hunters have to choose simultaneously between two hunting strategies: stag or hare. If one hunts a hare, he is sure to catch it regardless of the action of the other hunter, but in order to kill a stag both hunters have to join efforts. If one hunter chases after a stag alone, he comes back empty-handed. The dilemma emerges from the fact that, on the one hand, half a deer is better than one hare. On the other hand, hunting a hare involves no risk while the success of a stag hunt depends on the willingness of both hunters to cooperate.

Rousseau's parable is represented in game-theoretical terms in Table 1 below, with payoffs $\pi_{1}>\pi_{2} \geq \pi_{3}>\pi_{4}$. The stag hunt game has two purestrategy equilibria: "all stag" and "all hare." The "all stag" equilibrium payoff-dominates the "all hare" one, but the latter risk-dominates the former (Harsanyi and Selten, 1988). Nevertheless, it is not clear which of the two equilibria should be expected, as many other aspects -such as the number of hunters- must be considered in order to determine the plausibility of each equilibrium. For instance, when only two hunters are present, hunting a stag is preferred to hunting a hare provided that the second player also hunts stag with probability $\frac{1}{2}$ or higher. However, when $n$ hunters participate a stag is the optimal strategy only if there is a probability of at least $\frac{1}{2}$ that all other hunters hunt the stag. If each one hunts stag with an independent probability $p$, then this requires $p^{n-1}>\frac{1}{2}$. To illustrate, nine out of ten players must 
each hunt the stag with probability $p \gtrsim 0.93$ in order to make it worthy for the tenth hunter to join their efforts. As we can see, chasing after the stag is far from being the optimal strategy in a world with an increasingly large number of hunters.

Table 1: Stag Hunt Game

\begin{tabular}{c|l|l|}
\multicolumn{1}{c}{ Stag } & Hare \\
\cline { 2 - 3 } Stag & $\pi_{1}$ & $\pi_{4}$ \\
Hare & $\pi_{1}$ & $\pi_{2}$ \\
\cline { 2 - 3 } & $\pi_{2}$ & $\pi_{3}$ \\
& $\pi_{4}$ & $\pi_{3}$ \\
\cline { 2 - 3 } & &
\end{tabular}

The stag hunt game makes it clear that more risk-averse individuals might choose to engage less in civic activities or stop providing for public goods to protect themselves from the risk of others' defection. It is worth noting that, though the stag hunt game is static in nature, it is nonetheless able of mimic real world interactions where risk-dominant strategies are expected to prevail. The argument goes as follows: in a public good context, cooperating in its provision gives a higher payoff than defecting only if everyone cooperates. Otherwise, not cooperating is clearly advantageous, given that by definition an individual cannot be excluded from the public good. Since in the real world the probability that absolutely everyone contributes their share to the public good is very small (if not zero), the theory predicts rational individuals to be risk averse and thus restrain from participating. Paradoxically, cooperative behaviors are commonly observed in reality, which possibly indicates a lesser degree of risk aversion than predicted or the prevalence of myopic behaviors which may lead an individual to making "foolish" choices.

The link between participation and risk attitudes has been documented in several recent works. Most existing studies relating risk and contributions to public goods use a measure of natural risk, such as participation in the stock market. In line with the notion that perceived risk affects contributions to a public good, Charness and Villeval (2009) find that subjects who invest more in risky assets contribute more to public goods. A similar result based on a multi-period prisoner's dilemma has been reported by Sabater-Grande 
and Georgantzis (2002).

The second strand of literature upon which the present paper is built regards the relationship between risk aversion and cognitive ability. Kahneman and Tversky (1981, 1984, 1986) and Read et al. (2000) proposed a theory which foresees a strong relationship between the two. The theory embodies the trouble presented by a fraction of the population in bracketing choices in a broad manner, i.e., recognizing how risky decisions integrate with other assets like lifetime wealth, or conceptualizing and integrating future considerations with current goals. Narrow bracketing increases risk aversion as it impedes people from relating risky decisions with wealth, and increases myopic behaviors by augmenting people's difficulty in incorporating considerations about the future. However, there is empirical evidence that narrow bracketing is reduced when cognitive costs are lowered. For instance, Frederick (2005), Brañas-Garza et al. (2008), and Oechssler et al. (2009) find that, in general, individuals with low cognitive abilities tend to be more impatient and more unwilling to gamble, even in the domain of gains. This link between cognition and narrow bracketing provides for a mechanism directly relating risk aversion and cognitive ability.

Based on the two literature strands discussed above, it is fair to say that on one side risk aversion hinders the attainment of payoff-dominant equilibria by preventing cooperative behavior. On the other side, a positive link exists between risk aversion and cognitive ability. Put together, the theory implies that individuals with higher cognitive ability will have a lower degree of risk aversion, therefore engaging more in cooperative behaviors. The present paper aims at testing this claim empirically.

\section{Literature Review}

Studying the relationship between cognitive ability and pro-social behaviors is not new to economic, sociological, and psychological literature. In this regard, a variety of works suggest the existence of a positive link between educational attainment and charitable giving. Higher educational attainment has been consistently associated with a higher probability and larger amount of charitable giving (Brown and Lankford, 1992; Bekkers and Wiepking, 2011; 
James, 2011). However, it is possible that this association is driven by the individual's underlying cognitive ability rather than by educational attainment itself. This question is explored in a cross-sectional analysis using the Netherlands Panels Study 2003 (Wiepking and Maas, 2009). Their cognitive measurement was a 12-item vocabulary test with a mean score of $67 \%$ correct. Following previous results, higher education was initially shown to predict greater charitable giving. However, the authors found that this relationship could be explained by the larger financial resources and stronger verbal (cognitive) abilities of those displaying higher educational attainment.

Also Bekkers (2006) examination of charitable giving using the Family Survey of the Dutch Population included a measurement of verbal proficiency. Respondents were measured on their ability to select the correct synonym from a list of five alternatives. In a two-stage Heckman regression, the author finds that verbal proficiency was a positive significant predictor of both the presence of charitable giving among all respondents and the level of charitable giving among donors. This held true even when controlling for a variety of possible mediating pathways such as income, wealth, education, subjective health, and personality.

Cognitive ability has been associated with both volunteering and civic engagement as well. In an examination using the General Social Survey, Hauser (2000) finds that verbal ability, measured by a 10 -word vocabulary test, was associated with the number of organizations with which a respondent reported involvement (excluding labor unions). This relationship held even after controlling for the individuals' level of education. Verbal ability was also found to predict participation in the previous presidential election. Similarly, Hillygus (2005) employs a longitudinal study of college graduates to show that verbal SAT scores are associated with future political participation.

Denny (2003) found that a measurement of functional literacy (measured across multiple dimensions to estimate the respondents' abilities in extracting and using information from various texts) was positively associated with volunteering (given by participation in community or voluntary activities) after controlling for educational attainment. Such positive association between 
functional literacy and volunteering was constant across a variety of countries including Canada, Switzerland, Belgium, Chile, Czech Republic, Denmark, Finland, Germany, Great Britain, Hungary, Ireland, Italy, the Netherlands, New Zealand, Northern Ireland, Norway, Poland, Slovenia, Sweden, and the United States. In addition, studies of volunteering behavior limited to older adults have also found that volunteers score higher on tests of cognitive abilities (Glei et al., 2005; Hao, 2008).

\section{Data, Variables and Methodology}

\subsection{Data}

We use data from the second (2006) and third (2008) waves of the Survey on Health, Aging and Retirement in Europe (SHARE) ${ }^{4}$ which surveys people aged 50 and over in 12 European countries: Austria, Belgium, Czech Republic, Denmark, France, Germany, Italy, the Netherlands, Poland, Spain, Sweden, and Switzerland. ${ }^{5}$ SHARE is a multidisciplinary and cross-national database which provides detailed information on physical and mental health, socio-economic status, and social and family networks of respondents and their households. International comparisons are allowed by the inter-country standardization of all questions.

Furthermore, the third wave of SHARE, referred to as "SHARELIFE," provides retrospective information on respondents' life histories. It links in-

\footnotetext{
${ }^{4}$ This article uses data from SHARE 2006 and 2008, Wave 2 and 3, release 2.5.0 and 1 , respectively. The SHARE data collection has been primarily funded by the European Commission through the 5th Framework Programme (project QLK6-CT-2001-00360 in the thematic programme Quality of Life), through the 6th Framework Programme (projects SHARE-I3, RII-CT-2006-062193, COMPARE, CIT5- CT-2005-028857, and SHARELIFE, CIT4-CT-2006-028812) and through the 7th Framework Programme (SHARE-PREP, N ${ }^{o}$ 211909, SHARE-LEAP, $\mathrm{N}^{o} 227822$ and SHARE M4, $\mathrm{N}^{\circ}$ 261982). Additional funding from the U.S. National Institute on Aging (U01 AG09740-13S2, P01 AG005842, P01 AG08291, P30 AG12815, R21 AG025169, Y1-AG-4553-01, IAG BSR06-11 and OGHA 04-064) and the German Ministry of Education and Research as well as from various national sources is gratefully acknowledged (see www.share-project.org for a full list of funding institutions).

${ }^{5}$ Greece is dropped from the sample due to inconsistencies in the Greek questionnaire which make cross-country comparisons unreliable.
} 
Table 2: Summary Statistics

\begin{tabular}{rcccccc}
\hline Variable & Mean & Med. & Std. Dev. & Min & Max & N \\
\hline Civic Activities & 0.26426 & 0 & 0.55383 & 0 & 3 & 5328 \\
Immediate Recall & 5.1164 & 5 & 1.6661 & 0 & 10 & 5328 \\
Delayed Recall & 3.6381 & 4 & 1.9457 & 0 & 10 & 5328 \\
Numeracy & 3.4872 & 4 & 1.081 & 1 & 5 & 5328 \\
Books (at 10) & 2.2768 & 2 & 1.2475 & 1 & 5 & 5328 \\
Married & 0.64302 & 1 & 0.47915 & 0 & 1 & 5328 \\
Age & 61.212 & 60 & 8.6981 & 40 & 80 & 5328 \\
Female & 0.55706 & 1 & 0.49678 & 0 & 1 & 5328 \\
Financial Distress & 0.45477 & 0 & 0.498 & 0 & 1 & 5328 \\
Chronic cond. & 0.46171 & 0 & 0.49858 & 0 & 1 & 5328 \\
Education $\leq$ HS & 0.65672 & 1 & 0.47485 & 0 & 1 & 5328 \\
Education $>$ HS & 0.33934 & 0 & 0.47353 & 0 & 1 & 5328 \\
ADLs & 0.15822 & 0 & 0.6212 & 0 & 6 & 5328 \\
Unemployed & 0.034722 & 0 & 0.18309 & 0 & 1 & 5328 \\
Retired & 0.47166 & 0 & 0.49924 & 0 & 1 & 5328 \\
\hline
\end{tabular}

dividual micro data over the respondent's entire life with institutional macro data about the welfare state.

The current sample is made up of 5,328 persons ( $56 \%$ females) with complete information on cognitive abilities and civic engagement. The mean age is 63 for men and 62 for women. ${ }^{6}$ The summary statistics of the most relevant variables in our study are presented in Table 2.

\subsection{Variables}

\section{Measuring cognitive abilities}

The purpose of this paper is to analyze the association between cognitive abilities and volunteering in old age. SHARE provides detailed information on several indicators of cognition, such as mathematical and recall ability. In this section we describe the nature and construction of such indicators of cognitive abilities.

\footnotetext{
${ }^{6}$ Due to the more likely onset of degenerative diseases which may hinder pro-social behaviors, respondents aged 80 and above were excluded from the study.
} 
Mathematical ability, also referred to as numeracy, measures the respondent's capacity to perform basic numerical operations. It is an index composed of four questions which ask the respondent to calculate (1) $10 \%$ of a number; (2) one-half of a number; (3) the number for which another given number represents a fraction of two-thirds; and (4) the total amount after a two-year period given an initial amount and an annual interest rate of $10 \%$. Using these questions, a numeracy indicator ranging from one to five can be constructed (Dewey and Prince, 2005).

The indicator for recall ability, or memory, is in turn split up into two categories: immediate and delayed recall. Respondents are given a list of ten words and are asked to memorize them. After about a minute, the interviewer prompts the respondent to list the words she can remember. The immediate recall indicator is thus constructed based on the number of words recalled correctly, and ranges from 0 (respondent could not recall a single word from the list) to 10 (all words were correctly recalled by respondent). Unexpectedly for the respondent and after some more unrelated questions were answered, the interviewer returns to the word listing and asks the respondent to (again) name the words she can recall. This makes for a second indicator upon which the delayed recall score is constructed. ${ }^{7}$ The sample distributions of immediate and delayed recall, as well as numeracy score, are shown in Figure 1. In turn, Figure 2 provides graphical evidence of an unequal distribution of cognitive abilities across European countries, where a pseudo north-south gradient is formed.

\section{Measuring civic engagement}

A measure of civic engagement is constructed from a set of questions indicating the different social activities performed by the respondent in the month prior to the interview. Given the gratuitous character commonly attributed to pro-social and voluntary activities, we leave out of our study those activities with strong consumption aspects attached to them, such as

\footnotetext{
${ }^{7}$ All observations where the interviewer indicated that contextual factors may have impaired the respondent's cognitive performance during the interview were dropped from our study.
} 


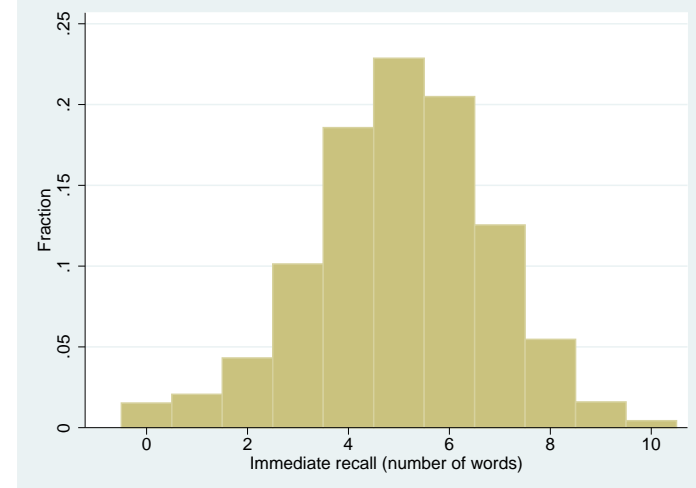

(a) Immediate recall

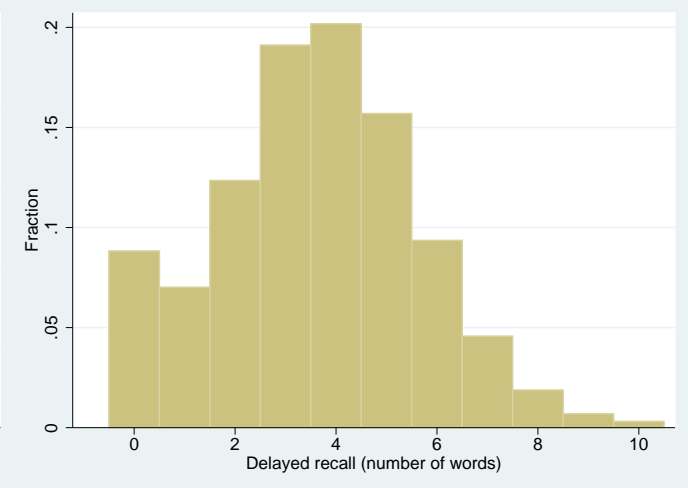

(b) Delayed recall

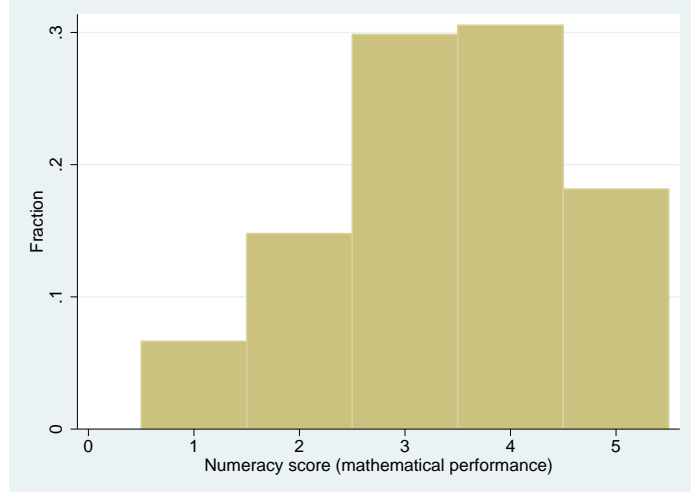

(c) Numeracy score

Figure 1: Distribution of cognitive indicators 


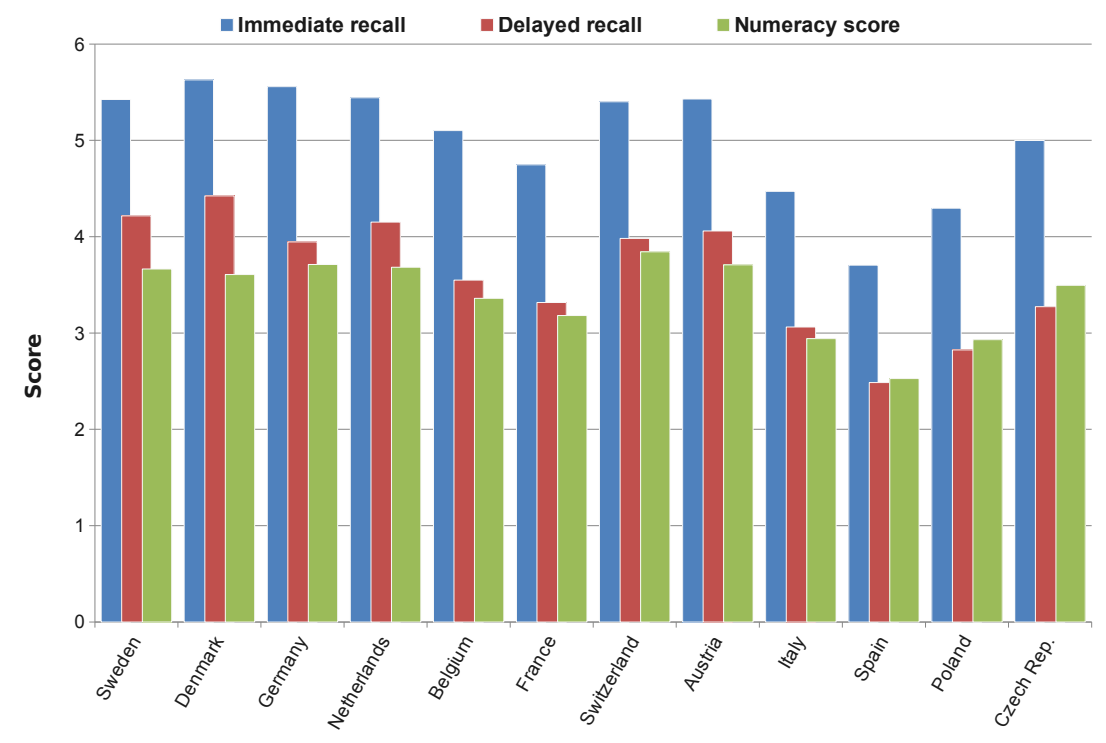

Figure 2: Average cognition score by country and cognitive indicator

attending an education or training course and participating in a sport, social, or other kind of club. We therefore consider three indicators of participation in society: $a$ ) doing voluntary or charity work; $b$ ) taking part in activities of a religious organization; and $c$ ) taking part in political or community-related organizations. From these three categories of participation, we construct a civic engagement index ranging from 0 (no participation) to 3 (involvement in all three categories). The average civic engagement score by each of the three cognitive indicators is shown in Figure 3; a clear positive association between civic participation and cognition can be perceived. ${ }^{8}$

\subsection{Methodology}

\section{Empirical specification}

In order to estimate the association between cognitive abilities and civic engagement we run a linear regression with a full set of controls, which in-

\footnotetext{
${ }^{8}$ Moreover, using information on the amount of financial risks individual respondents declare to be willing to take when saving or making investments, we find a statistically significant negative correlation (at the $0.1 \%$ level) between pro-social activities and risk aversion. This is consistent with what has been previously found in the literature and exposed in Section 2.
} 


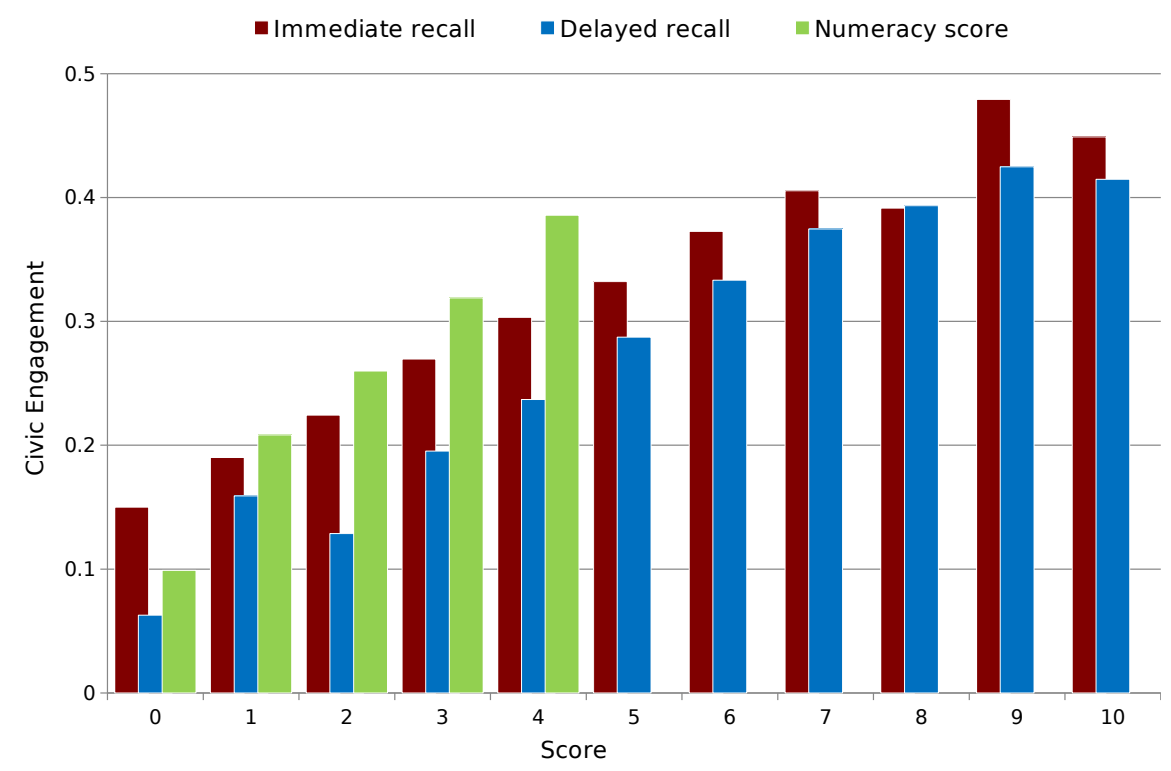

Figure 3: Average civic engagement by cognitive indicator for the pooled sample

clude, among others, indicators of the respondent's socio-economic status as well as health conditions.

Our econometric specification is

$$
Y_{i}=\beta_{1} C_{i}+X_{i}^{T} \beta_{2}+U_{i}
$$

where $Y$ represents the number of activities to which the respondent participates, $U$ is a disturbance term, and $X \equiv\left\{X_{k}\right\}_{k=1}^{K}$ is a vector of socioeconomic and demographic characteristics which we discuss in detail below. The variable of interest, $C_{i}$, denotes the respondent's score for each of the three measures of cognitive abilities.

Table 3 shows the results of the OLS regression of civic engagement on each of the three indicators for cognition. Such results evidence a positive association between cognition and civic participation in old age, with the largest effects given by the mathematical indicator of cognitive abilities (i.e., the numeracy score). Throughout this study, we control for the following characteristics of the respondent: marital status (dummy, equals one if the 
respondent is married and zero otherwise); age; gender (dummy, equals one for females and zero otherwise); number of years of education; number of chronic conditions (dummy, equals one if the respondent suffers from more than two chronic conditions, and zero otherwise); an additional health indicator which measures the hardship met in performing activities of daily living (ADLs); employment status (dummy, equals one if the respondent is unemployed, and zero otherwise); a retirement dummy (equals one if the respondent is retired, and zero otherwise); financial distress (measures the ability of households to "make ends meet" at the end of the month); and household income (split into intra-country quintiles). Furthermore, all regressions are estimated using calibrated weights and, although not explicitly shown in equation 1, country dummies were included in all estimations to account for cultural differences between countries. ${ }^{9}$

However, the aforementioned OLS estimation does not take into account the fact that cognition and civic engagement can be endogenous, which, if not addressed properly, results in biased parameters and impedes any possible statement of causality between the two. For instance, reverse causality might exist, as people who engage more in society might be more likely to expose themselves to mentally stimulating situations and activities and will thus perform better in cognitive tests. Omitted variables and confounding factors for both cognitive abilities and civic engagement -such as culture and genetics- might also arise and cast doubt on our linear regression estimates, not to mention non-random selection mechanisms which might have made more likely for people with a certain cognition level to participate in the survey. In order to account for such issues and obtain consistent estimates for our structural parameters, an instrumental variables approach is adopted in this study. The two-stage instrumental variable empirical model is then given by the structural equation 1 and complemented by the following first-stage specification:

$$
C_{i}=Z_{i}^{T} \gamma_{1}+X_{i}^{T} \gamma_{2}+V_{i}
$$

\footnotetext{
${ }^{9}$ Survey weights are provided in SHARE with the aim of removing bias from the survey sample and thus making the resulting statistics more representative of the population as a whole.
} 
Table 3: OLS regressions of civic engagement on the three cognitive indicators

\begin{tabular}{|c|c|c|c|}
\hline Variable & $\begin{array}{l}\text { Model } 1 \\
\text { Civic Eng. }\end{array}$ & $\begin{array}{l}\text { Model } 2 \\
\text { Civic Eng. }\end{array}$ & $\begin{array}{l}\text { Model } 3 \\
\text { Civic Eng. }\end{array}$ \\
\hline Immediate recall & $\begin{array}{c}0.025^{* * *} \\
(0.004)\end{array}$ & & \\
\hline Delayed recall & & $\begin{array}{c}0.016^{* * *} \\
(0.004)\end{array}$ & \\
\hline Numeracy score & & & $\begin{array}{c}0.032^{* * *} \\
(0.007)\end{array}$ \\
\hline Married & $\begin{array}{l}-0.006 \\
(0.014)\end{array}$ & $\begin{array}{l}-0.005 \\
(0.014)\end{array}$ & $\begin{array}{c}-0.007 \\
(0.014)\end{array}$ \\
\hline Age & $\begin{array}{c}0.003^{* *} \\
(0.001)\end{array}$ & $\begin{array}{c}0.002^{* *} \\
(0.001)\end{array}$ & $\begin{array}{l}0.002^{*} \\
(0.001)\end{array}$ \\
\hline Female & $\begin{array}{l}-0.017 \\
(0.013)\end{array}$ & $\begin{array}{l}-0.015 \\
(0.013)\end{array}$ & $\begin{array}{c}-0.001 \\
(0.013)\end{array}$ \\
\hline Financial distress & $\begin{array}{c}-0.043^{* * *} \\
(0.015)\end{array}$ & $\begin{array}{c}-0.046^{* * *} \\
(0.015)\end{array}$ & $\begin{array}{c}-0.042^{* * *} \\
(0.015)\end{array}$ \\
\hline Chronic disease & $\begin{array}{l}-0.007 \\
(0.014)\end{array}$ & $\begin{array}{l}-0.008 \\
(0.014)\end{array}$ & $\begin{array}{c}-0.009 \\
(0.014)\end{array}$ \\
\hline Education & $\begin{array}{c}0.057^{* * *} \\
(0.009)\end{array}$ & $\begin{array}{c}0.061^{* * *} \\
(0.009)\end{array}$ & $\begin{array}{c}0.058^{* * *} \\
(0.009)\end{array}$ \\
\hline ADLs & $\begin{array}{c}-0.020^{* *} \\
(0.010)\end{array}$ & $\begin{array}{c}-0.022^{* *} \\
(0.010)\end{array}$ & $\begin{array}{c}-0.020^{* *} \\
(0.010)\end{array}$ \\
\hline Unemployed & $\begin{array}{l}-0.027 \\
(0.035)\end{array}$ & $\begin{array}{c}-0.024 \\
(0.035)\end{array}$ & $\begin{array}{l}-0.025 \\
(0.035)\end{array}$ \\
\hline Retired & $\begin{array}{c}0.005 \\
(0.018)\end{array}$ & $\begin{array}{c}0.007 \\
(0.018)\end{array}$ & $\begin{array}{c}0.006 \\
(0.018)\end{array}$ \\
\hline Income quintile & $\begin{array}{c}-0.011^{* *} \\
(0.005)\end{array}$ & $\begin{array}{c}-0.010 * * \\
(0.005)\end{array}$ & $\begin{array}{c}-0.011^{* *} \\
(0.005)\end{array}$ \\
\hline Constant & $\begin{array}{l}-0.112 \\
(0.108)\end{array}$ & $\begin{array}{c}0.05 \\
(0.081)\end{array}$ & $\begin{array}{c}0.017 \\
(0.082)\end{array}$ \\
\hline Obs. & 6650 & 6651 & 6653 \\
\hline $\mathrm{F}$ & 24.93 & 24.16 & 24.50 \\
\hline Prob $>F$ & 0.000 & 0.000 & 0.000 \\
\hline Centered $R^{2}$ & 0.076 & 0.074 & 0.075 \\
\hline
\end{tabular}

Notes:

Standard errors in parentheses

${ }^{* * *} p<0.01,{ }^{* *} p<0.05,{ }^{*} p<0.1$ 
where $Z \equiv\left\{Z_{l}\right\}_{l=1}^{L}$ is a vector of instruments and $V$ represents the error term.

We use retrospective information on the respondent's life -available from SHARELIFE - to instrument our indicators of cognitive ability. In particular, we exploit information about the number of books ${ }^{10}$ at the respondent's the place of residence when the she was ten years old. The justification for using this as our instrument rests upon the assumption that the number of books present at the respondent's home during childhood affects civic participation in later adulthood only through its potential effect on the respondent's cognitive abilities. ${ }^{11}$ Put differently, in order for it to be a valid instrument, it must be directly related to the respondent's cognition (relevance requirement) and influence her civic participation only indirectly through its effects on cognition (exogeneity assumption). As shown in Figure 4, a clear positive relationship exists between cognitive levels in old age and the number of books at home during childhood.

We address the endogeneity issues in our data by resorting to a twostep Generalized Method of Moments (GMM) instrumental variables estimation with robust standard errors (Hansen, 1982). As opposed to the more commonly-used two-stage least squares (2SLS), GMM allows for an efficient estimation in the presence of heteroskedasticity of unknown form. In using survey data, such as SHARE, we have enough reasons to presume the nonhomoskedasticity of our residuals. ${ }^{12}$ Accordingly, the robust option of the ivreg2 command in Stata is employed in order to obtain standard errors and statistics which are robust to the presence of arbitrary heteroskedasticity.

\footnotetext{
${ }^{10}$ Magazines, newspapers, and school books are explicitly excluded from the question.

${ }^{11}$ Brunello et al. (2012) findings support the claim that the availability of books in the household during childhood captures the development of cognitive abilities rather than the presence of financial constraints. In other words, using international data on cognitive test scores, books are found to be significant predictors of cognitive development, even after controlling for parental education and employment. The importance and lasting effects of early life investments are also emphasized by Cunha and Heckman (2007), Cunha et al. (2010), and Heckman et al. (2012).

${ }^{12}$ See, for instance, Wooldridge (2001) and Wooldridge (2002, p. 193).
} 


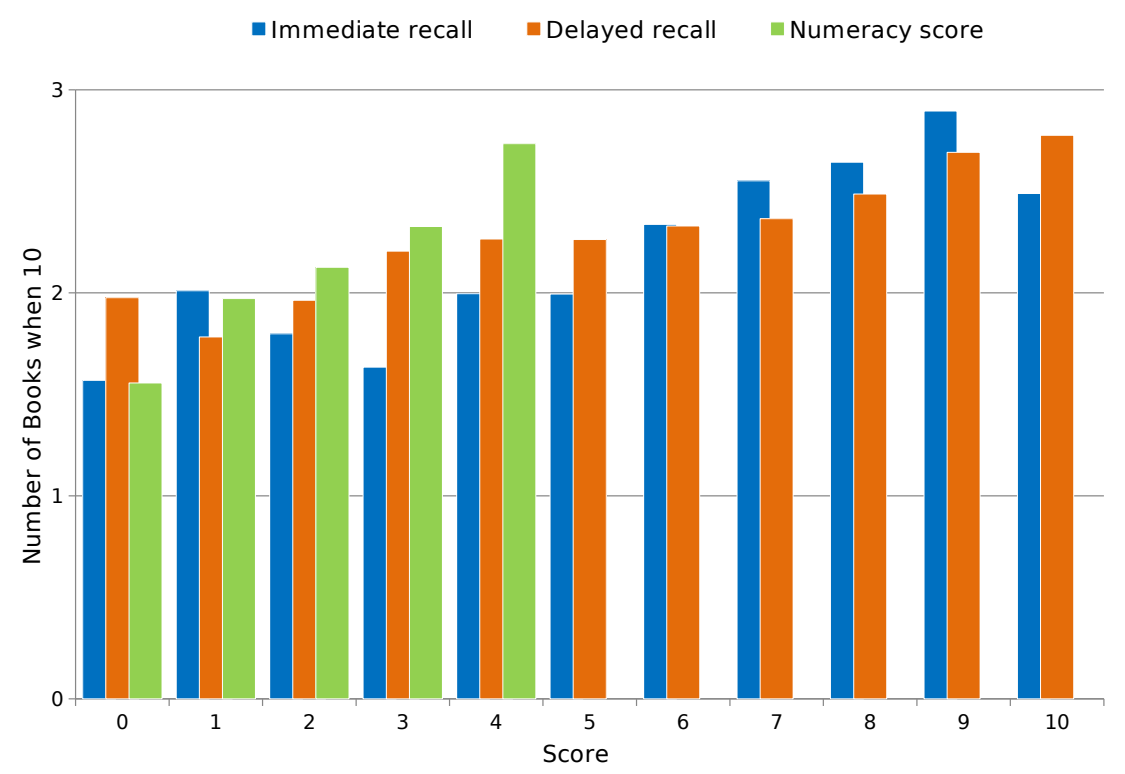

Figure 4: Average number of books when aged 10 by cognition level

\section{Results}

\subsection{First stage results}

Table 4 shows the estimated coefficients from the first stage regression of civic engagement on the instrument and the control variables in our model. The results confirm the relevance of the chosen instrument for all indicators of cognition (namely immediate recall, delayed recall, and numeracy). In particular, having more books at home during childhood is shown to be a strong predictor of higher mathematical ability and better memory levels in old age.

\subsection{Second stage results}

Table 5 shows the results of the second stage GMM procedure. Here, civic engagement is regressed on the estimated level of cognition obtained from the first stage regression in the previous subsection. As long as the instrument is valid, such cognition estimates should now be free from most endogeneity issues. 
Table 4: First stage regressions instrumenting cognition with number of books at home when the respondent was ten years old

\begin{tabular}{|c|c|c|c|}
\hline Variable & $\begin{array}{c}\text { Model } 1 \\
\text { Immediate recall }\end{array}$ & $\begin{array}{c}\text { Model } 2 \\
\text { Delayed recall }\end{array}$ & $\begin{array}{c}\text { Model 3 } \\
\text { Numeracy score }\end{array}$ \\
\hline Number of books & $\begin{array}{c}0.141^{* * *} \\
(0.021)\end{array}$ & $\begin{array}{c}0.125^{* * *} \\
(0.024)\end{array}$ & $\begin{array}{c}0.115^{* * *} \\
(0.013)\end{array}$ \\
\hline Married & $\begin{array}{c}0.119^{*} \\
(0.047)\end{array}$ & $\begin{array}{c}0.123^{*} \\
(0.055)\end{array}$ & $\begin{array}{c}0.143^{* * *} \\
(0.030)\end{array}$ \\
\hline Age & $\begin{array}{c}-0.047^{* * *} \\
(0.004)\end{array}$ & $\begin{array}{c}-0.056^{* * *} \\
(0.004)\end{array}$ & $\begin{array}{c}-0.015^{* * *} \\
(0.002)\end{array}$ \\
\hline Female & $\begin{array}{c}0.378^{* * *} \\
(0.045)\end{array}$ & $\begin{array}{c}0.501^{* * *} \\
(0.053)\end{array}$ & $\begin{array}{c}-0.238^{* * *} \\
(0.029)\end{array}$ \\
\hline Financial distress & $\begin{array}{c}-0.151^{* *} \\
(0.052)\end{array}$ & $\begin{array}{l}-0.019 \\
(0.061)\end{array}$ & $\begin{array}{c}-0.144^{* * *} \\
(0.034)\end{array}$ \\
\hline Chronic disease & $\begin{array}{l}-0.092^{*} \\
(0.046)\end{array}$ & $\begin{array}{l}-0.119^{*} \\
(0.054)\end{array}$ & $\begin{array}{l}-0.045 \\
(0.030)\end{array}$ \\
\hline Education & $\begin{array}{c}0.342^{* * *} \\
(0.033)\end{array}$ & $\begin{array}{c}0.412^{* * *} \\
(0.039)\end{array}$ & $\begin{array}{c}0.295^{* * *} \\
(0.021)\end{array}$ \\
\hline ADLs & $\begin{array}{c}-0.135^{* *} \\
(0.041)\end{array}$ & $\begin{array}{c}-0.138^{* *} \\
(0.046)\end{array}$ & $\begin{array}{c}-0.120^{* * *} \\
(0.026)\end{array}$ \\
\hline Unemployed & $\begin{array}{l}-0.006 \\
(0.127)\end{array}$ & $\begin{array}{l}-0.148 \\
(0.140)\end{array}$ & $\begin{array}{l}-0.048 \\
(0.077)\end{array}$ \\
\hline Retired & $\begin{array}{c}0.171^{* *} \\
(0.060)\end{array}$ & $\begin{array}{l}0.151^{*} \\
(0.074)\end{array}$ & $\begin{array}{c}0.099^{*} \\
(0.040)\end{array}$ \\
\hline Income quintile & $\begin{array}{l}0.045^{* *} \\
(0.016)\end{array}$ & $\begin{array}{l}0.045^{*} \\
(0.019)\end{array}$ & $\begin{array}{c}0.046^{* * *} \\
(0.010)\end{array}$ \\
\hline Constant & $\begin{array}{c}6.551^{* * *} \\
(0.249)\end{array}$ & $\begin{array}{c}5.067^{* * *} \\
(0.297)\end{array}$ & $\begin{array}{c}3.437^{* * *} \\
(0.164)\end{array}$ \\
\hline Obs. & 4475 & 4476 & 4475 \\
\hline $\mathrm{F}$ & 77.25 & 74.58 & 92.21 \\
\hline Prob $>F$ & 0.000 & 0.000 & 0.000 \\
\hline$r k$ F-stat. & 46.971 & 26.374 & 80.413 \\
\hline Centered $R^{2}$ & 0.267 & 0.256 & 0.288 \\
\hline
\end{tabular}

Notes:

Standard errors in parentheses

${ }^{* * *} p<0.01,{ }^{* *} p<0.05,{ }^{*} p<0.1$ 
All three cognition indicators seem to exert a strong, positive, significant, and seemingly causal effect on the degree of civic engagement of individuals. The higher an individual's mathematical and memory levels, the more likely it is that she will reach out to her community, with long-lasting memory and numeracy as the indicators with the strongest effects on civic participation.

Interestingly enough, older people in the lower income quantiles are more likely to get involved in their society. This appears as an arguably counterintuitive result which would need further exploration before any conclusions are drawn from it.

\section{IV tests}

For all three measures of cognitive abilities, the hypothesis that cognition can be treated as exogenous in the main regression is always rejected at traditional significance levels $(p$-value $<0.01)$. This serves as supporting evidence in favor of our chosen empirical methods and procedures.

Our instrument, number of books when the respondent was ten, appears to be relevant to cognition as confirmed by our first stage estimates. Moreover, Stock and Yogo (2005) weak identification test is passed in all cases, as all $F$-statistics from our first stage regressions are well above the critical values. Furthermore, all $F$-values given by the Kleibergen and Paap rk statistic in the first-stage regressions surpass the threshold value of $10 .{ }^{13} \hat{i}^{14}$ Nevertheless, given that the model is exactly identified, we are unable to provide statistical evidence for the excludability of our instrument from the main equation. In what follows we review different attempts to tackle this issue.

\footnotetext{
${ }^{13}$ Staiger and Stock (1997) show that $F$-statistics from the first stage regression should be at least ten for weak identification not to be considered a problem. This has become the "rule of thumb" for the identification of weak instrument problems, especially for situations where the i.i.d. property of standard errors cannot be reasonably claimed.

${ }^{14}$ Given its robustness to heteroskedasticity, the Kleibergen and Paap rk statistic is the preferred indicator in our case (Kleibergen and Paap, 2006).
} 
Table 5: Second stage regressions instrumenting cognition with number of books at home when the respondent was ten years old

\begin{tabular}{|c|c|c|c|}
\hline Variable & $\begin{array}{l}\text { Model } 1 \\
\text { Civic Eng. }\end{array}$ & $\begin{array}{l}\text { Model } 2 \\
\text { Civic Eng. }\end{array}$ & $\begin{array}{l}\text { Model } 3 \\
\text { Civic Eng }\end{array}$ \\
\hline Immediate recall & $\begin{array}{c}0.265^{* * *} \\
(0.069)\end{array}$ & & \\
\hline Delayed recall & & $\begin{array}{c}0.300^{* * *} \\
(0.087)\end{array}$ & \\
\hline Numeracy score & & & $\begin{array}{c}0.331^{* * *} \\
(0.080)\end{array}$ \\
\hline Married & $\begin{array}{l}-0.023 \\
(0.022)\end{array}$ & $\begin{array}{l}-0.028 \\
(0.025)\end{array}$ & $\begin{array}{c}-0.038^{*} \\
(0.022)\end{array}$ \\
\hline Age & $\begin{array}{c}0.014^{* * *} \\
(0.004)\end{array}$ & $\begin{array}{c}0.019^{* * *} \\
(0.005)\end{array}$ & $\begin{array}{c}0.007^{* * *} \\
(0.002)\end{array}$ \\
\hline Female & $\begin{array}{c}-0.121^{* * *} \\
(0.034)\end{array}$ & $\begin{array}{c}-0.171^{* * * *} \\
(0.050)\end{array}$ & $\begin{array}{c}0.056^{* *} \\
(0.027)\end{array}$ \\
\hline Financial distress & $\begin{array}{l}-0.007 \\
(0.024)\end{array}$ & $\begin{array}{l}-0.041 \\
(0.025)\end{array}$ & $\begin{array}{c}0.001 \\
(0.024)\end{array}$ \\
\hline Chronic disease & $\begin{array}{c}0.012 \\
(0.021)\end{array}$ & $\begin{array}{c}0.023 \\
(0.025)\end{array}$ & $\begin{array}{c}0.002 \\
(0.019)\end{array}$ \\
\hline Education & $\begin{array}{l}-0.041 \\
(0.032)\end{array}$ & $\begin{array}{c}-0.074^{*} \\
(0.044)\end{array}$ & $\begin{array}{l}-0.048 \\
(0.031)\end{array}$ \\
\hline ADLs & $\begin{array}{c}0.001 \\
(0.016)\end{array}$ & $\begin{array}{c}0.006 \\
(0.019)\end{array}$ & $\begin{array}{c}0.003 \\
(0.014)\end{array}$ \\
\hline Unemployed & $\begin{array}{l}-0.015 \\
(0.053)\end{array}$ & $\begin{array}{c}0.028 \\
(0.059)\end{array}$ & $\begin{array}{c}0.000 \\
(0.049)\end{array}$ \\
\hline Retired & $\begin{array}{l}-0.025 \\
(0.029)\end{array}$ & $\begin{array}{l}-0.025 \\
(0.033)\end{array}$ & $\begin{array}{l}-0.012 \\
(0.027)\end{array}$ \\
\hline Income quintile & $\begin{array}{c}-0.023^{* * *} \\
(0.008)\end{array}$ & $\begin{array}{c}-0.024^{* * *} \\
(0.009)\end{array}$ & $\begin{array}{c}-0.025^{* * *} \\
(0.008)\end{array}$ \\
\hline Constant & $\begin{array}{c}-1.881^{* * *} \\
(0.488)\end{array}$ & $\begin{array}{c}-1.666^{* * *} \\
(0.482)\end{array}$ & $\begin{array}{c}-1.286^{* * *} \\
(0.316)\end{array}$ \\
\hline Obs. & 4475 & 4476 & 4475 \\
\hline AR F-test & 0.000 & 0.000 & 0.000 \\
\hline Hansen J & $\mathrm{n} / \mathrm{a}$ & $\mathrm{n} / \mathrm{a}$ & $\mathrm{n} / \mathrm{a}$ \\
\hline
\end{tabular}

Notes:

Standard errors in parentheses

${ }^{* * *} p<0.01,{ }^{* *} p<0.05,{ }^{*} p<0.1$ 


\subsection{Robustness}

The robustness of the positive effect of cognition on civic engagement is made evident by its persistence on both our first stage OLS and second stage GMM results, regardless of the different indicators used to denote cognition.

Yet, in order to overidentify the model and thus be able to run a SarganHansen test of overidentifying restrictions, an additional instrument would be required. This will allow us to provide a clearer and more convincing statistical proof of the validity of our model. The natural candidates in our case would be the respondent's relative mathematical and language position to others when she was ten years old -information readily available in SHARELIFE. However, these variables were not considered as instruments for two main reasons. Firstly, the fact that they are very similar in nature to our instrument (number of books at age ten) makes it hard to trust the Hansen $\mathrm{J}$ test -recall that such procedure assumes the validity of at least one instrument in order to test the overidentifying restrictions. In other words, given their similarity in design and scope, assuming that one of the instruments is valid will likely imply that the others are as well. For this reason, heterogeneity of instruments is usually advised as a more credible framework for the Hansen $J$ test of overidentifying restrictions.

Secondly, the empirical inclusion of relative mathematical and linguistic position at age ten seems to lead to a violation of the monotonicity assumption: their association to cognition in the first stage OLS regression seems to run in the opposite direction to what would otherwise be commonly believed (e.g., better mathematical and language position relative to others in childhood is negatively related to all three cognition indicators in later adulthood). ${ }^{15}$ Intuitively, treatment in an instrumental variables exercise is designed to produce a certain effect in a given population. When such effect goes -against all forecasts- in the opposite direction, a contravention of the monotonicity assumption is said to exist and the results are regarded as invalid.

\footnotetext{
${ }^{15}$ Moreover, the inclusion of these variables as instruments causes the model not to reject the exogeneity of cognition assumption at the $5 \%$ significance level.
} 
Both individually and when combined with the number-of-books instrument, mathematical and language ranking in childhood fall short from instrumental validity. Thus, we find no statistical grounds whatsoever for including these variables as additional instruments in our model.

An alternative strategy to overidentify our model is to instrumentalize the cognition level of each respondent also with their reported height. ${ }^{16}$ Several studies have reported a strong correlation between height and cognitive abilities (Abbott et al., 1998; Case and Paxson, 2008b,a; Maurer, 2010). In this logic, the validity of height as an instrument will depend on its relation to cognition levels and the conjecture that height is not a relevant factor to the engagement-in-society decision. That is, independent of their height, everyone has the same possibilities to engage in volunteering activities or participate in a political or religious organization.

Table 6 displays the results of the second stage regressions using both height and books when aged ten as instruments for cognition. The results are satisfactory in that the positive and statistically significant effect of cognition on civic engagement is confirmed and the Hansen $\mathrm{J}$ test fails to reject the exogeneity of instruments assumption for all three regressions (with $p$-values of $0.95,0.57$, and 0.87 for immediate recall, delayed recall, and numeracy, respectively). However, the low significance level of height in the first stage regressions given in Table 7 seems to point to an apparent weak instrument problem, in particular for the second model where cognition is proxied by delayed recall. This is confirmed by the violation of the "rule of thumb" requiring the $F$-statistics in the first stage regressions to be greater than ten; in our case, only in the second model does the $r k F$-statistic falls slightly below this level (with a value of 9.12).

In the presence of weak instruments, inference should be made with caution. Weak -as well as too many- instruments may cause the instrumental variables estimator to be more biased than its OLS counterpart. Since standard errors from the first stage are not considered in the second-stage estimation, the resulting estimated variance will be biased downwards; this

\footnotetext{
${ }^{16}$ SHARE provides information on basic physical attributes of respondents, such as height, weight, and grip strength.
} 
Table 6: Second stage regressions instrumenting cognition with height and number of books at home when the respondent was ten years old

\begin{tabular}{|c|c|c|c|}
\hline Variable & $\begin{array}{l}\text { Model } 1 \\
\text { Civic Eng. }\end{array}$ & $\begin{array}{l}\text { Model } 2 \\
\text { Civic Eng. }\end{array}$ & $\begin{array}{l}\text { Model } 3 \\
\text { Civic Eng. }\end{array}$ \\
\hline Immediate recall & $\begin{array}{c}0.296^{* * *} \\
(0.085)\end{array}$ & & \\
\hline Delayed recall & & $\begin{array}{c}0.337^{* * * *} \\
(0.111)\end{array}$ & \\
\hline Numeracy score & & & $\begin{array}{c}0.397^{* * *} \\
(0.103)\end{array}$ \\
\hline Married & $\begin{array}{c}-0.02 \\
(0.027)\end{array}$ & $\begin{array}{l}-0.011 \\
(0.030)\end{array}$ & $\begin{array}{l}-0.033 \\
(0.027)\end{array}$ \\
\hline Age & $\begin{array}{c}0.014^{* * *} \\
(0.004)\end{array}$ & $\begin{array}{c}0.019^{* * *} \\
(0.007)\end{array}$ & $\begin{array}{c}0.007^{* * *} \\
(0.002)\end{array}$ \\
\hline Female & $\begin{array}{c}-0.129 * * * \\
(0.039)\end{array}$ & $\begin{array}{c}-0.183^{* * *} \\
(0.060)\end{array}$ & $\begin{array}{c}0.067^{* *} \\
(0.033)\end{array}$ \\
\hline Financial distress & $\begin{array}{l}-0.024 \\
(0.026)\end{array}$ & $\begin{array}{l}-0.037 \\
(0.030)\end{array}$ & $\begin{array}{c}0.003 \\
(0.028)\end{array}$ \\
\hline Chronic disease & $\begin{array}{c}0.016 \\
(0.025)\end{array}$ & $\begin{array}{c}0.036 \\
(0.031)\end{array}$ & $\begin{array}{c}0.01 \\
(0.023)\end{array}$ \\
\hline Education & $\begin{array}{l}-0.061 \\
(0.039)\end{array}$ & $\begin{array}{c}-0.087^{*} \\
(0.053)\end{array}$ & $\begin{array}{c}-0.076^{* *} \\
(0.039)\end{array}$ \\
\hline ADLs & $\begin{array}{c}0.013 \\
(0.021)\end{array}$ & $\begin{array}{c}0.022 \\
(0.026)\end{array}$ & $\begin{array}{c}0.007 \\
(0.017)\end{array}$ \\
\hline Unemployed & $\begin{array}{l}-0.033 \\
(0.065)\end{array}$ & $\begin{array}{c}0.002 \\
(0.072)\end{array}$ & $\begin{array}{l}-0.021 \\
(0.060)\end{array}$ \\
\hline Retired & $\begin{array}{l}-0.025 \\
(0.035)\end{array}$ & $\begin{array}{c}-0.014 \\
(0.040)\end{array}$ & $\begin{array}{l}-0.015 \\
(0.033)\end{array}$ \\
\hline Income quintile & $\begin{array}{c}-0.026^{* * *} \\
(0.010)\end{array}$ & $\begin{array}{c}-0.026^{* *} \\
(0.012)\end{array}$ & $\begin{array}{c}-0.031^{* * *} \\
(0.010)\end{array}$ \\
\hline Constant & $\begin{array}{c}-1.981^{* * *} \\
(0.578)\end{array}$ & $\begin{array}{c}-1.843^{* * *} \\
(0.619)\end{array}$ & $\begin{array}{c}-1.493^{* * *} \\
(0.406)\end{array}$ \\
\hline Obs. & 3534 & 3535 & 3534 \\
\hline AR F-test & 0.000 & 0.000 & 0.000 \\
\hline Hansen J & 0.947 & 0.567 & 0.873 \\
\hline
\end{tabular}

Notes:

Standard errors in parentheses

${ }^{* * *} p<0.01,{ }^{* *} p<0.05,{ }^{*} p<0.1$ 
Table 7: First stage regressions instrumenting cognition with height and number of books at home when the respondent was ten years old

\begin{tabular}{|c|c|c|c|}
\hline Variable & $\begin{array}{c}\text { Model } 1 \\
\text { Immediate recall }\end{array}$ & $\begin{array}{c}\text { Model } 2 \\
\text { Delayed recall }\end{array}$ & $\begin{array}{c}\text { Model 3 } \\
\text { Numeracy score }\end{array}$ \\
\hline Number of books & $\begin{array}{c}0.128^{* * *} \\
(0.023)\end{array}$ & $\begin{array}{c}0.102^{* * *} \\
(0.028)\end{array}$ & $\begin{array}{c}0.098^{* * *} \\
(0.014)\end{array}$ \\
\hline Height & $\begin{array}{c}0.007^{*} \\
(0.004)\end{array}$ & $\begin{array}{c}0.009^{*} \\
(0.005)\end{array}$ & $\begin{array}{c}0.006^{* *} \\
(0.003)\end{array}$ \\
\hline Married & $\begin{array}{c}0.139^{* * *} \\
(0.054)\end{array}$ & $\begin{array}{c}0.098 \\
(0.063)\end{array}$ & $\begin{array}{c}0.137^{* * *} \\
(0.034)\end{array}$ \\
\hline Age & $\begin{array}{c}-0.044^{* * *} \\
(0.004)\end{array}$ & $\begin{array}{c}-0.053^{* * *} \\
(0.005)\end{array}$ & $\begin{array}{c}-0.014^{* * *} \\
(0.003)\end{array}$ \\
\hline Female & $\begin{array}{c}0.439^{* * *} \\
(0.069)\end{array}$ & $\begin{array}{c}0.580^{* * *} \\
(0.082)\end{array}$ & $\begin{array}{c}-0.166^{* * *} \\
(0.043)\end{array}$ \\
\hline Financial distress & $\begin{array}{l}-0.067 \\
(0.058)\end{array}$ & $\begin{array}{l}-0.017 \\
(0.069)\end{array}$ & $\begin{array}{c}-0.119^{* * * *} \\
(0.037)\end{array}$ \\
\hline Chronic disease & $\begin{array}{c}-0.08 \\
(0.051)\end{array}$ & $\begin{array}{c}-0.129 * * \\
(0.061)\end{array}$ & $\begin{array}{l}-0.045 \\
(0.034)\end{array}$ \\
\hline Education & $\begin{array}{c}0.348^{* * *} \\
(0.038)\end{array}$ & $\begin{array}{c}0.387^{* * *} \\
(0.045)\end{array}$ & $\begin{array}{c}0.296^{* * *} \\
(0.023)\end{array}$ \\
\hline ADLs & $\begin{array}{c}-0.154^{* * *} \\
(0.048)\end{array}$ & $\begin{array}{c}-0.162^{* * *} \\
(0.053)\end{array}$ & $\begin{array}{c}-0.101^{* * *} \\
(0.028)\end{array}$ \\
\hline Unemployed & $\begin{array}{c}0.049 \\
(0.146)\end{array}$ & $\begin{array}{l}-0.062 \\
(0.155)\end{array}$ & $\begin{array}{c}0.007 \\
(0.088)\end{array}$ \\
\hline Retired & $\begin{array}{c}0.190^{* * *} \\
(0.066)\end{array}$ & $\begin{array}{l}0.139 * \\
(0.083)\end{array}$ & $\begin{array}{c}0.120^{* * *} \\
(0.044)\end{array}$ \\
\hline Income quintile & $\begin{array}{c}0.058^{* * *} \\
(0.018)\end{array}$ & $\begin{array}{c}0.052^{* *} \\
(0.021)\end{array}$ & $\begin{array}{c}0.054^{* * *} * \\
(0.012)\end{array}$ \\
\hline Constant & $\begin{array}{c}5.066^{* * *} \\
(0.788)\end{array}$ & $\begin{array}{c}3.546^{* * *} \\
(0.925)\end{array}$ & $\begin{array}{c}2.445^{* * *} \\
(0.487)\end{array}$ \\
\hline Obs. & 3534 & 3535 & 3534 \\
\hline $\mathrm{F}$ & 56.91 & 54.28 & 68.59 \\
\hline Prob $>$ F & 0.000 & 0.000 & 0.000 \\
\hline$r k$ F-stat. & 17.248 & 9.117 & 27.213 \\
\hline Centered $R^{2}$ & 0.263 & 0.246 & 0.291 \\
\hline
\end{tabular}

Notes:

Standard errors in parentheses

${ }^{* * *} p<0.01,{ }^{* *} p<0.05,{ }^{*} p<0.1$ 
would in turn cause the null hypothesis to be too often rejected.

Albeit still an area of intense ongoing research, various methods are currently available to carry out inference in the presence of weak instruments. For instance, two alternatives which are robust to this problem -in the case of one endogenous regressor- are the Anderson-Rubin test (Anderson and Rubin, 1949) and the more recent conditional likelihood ratio (CLR) (Moreira, 2003). Both procedures build confidence intervals that allow for fully robust inference even in the presence of weak instruments. Econometrical preferences have lately sided with the latter test since it has been shown to be approximately optimal, dominating the other alternatives in terms of power (Andrews et al., 2008).

In what follows, both methods are employed to correct for the presence of weak instruments in our models. The results of the CLR, AR, and J tests for all three indicators of cognition are given in Table 8. ${ }^{17}$ Notably, both the CLR and the AR tests confirm the robustness of the previously-obtained results in that cognition is a significant determinant of civic participation. Moreover, the $\mathrm{J}$ test reinforces our exogeneity-of-instruments presumption in all three cases.

Table 8: Weak instrument robust tests for the cognition parameters ( $p$ values)

\begin{tabular}{rccc}
\hline Test & Imm. Recall & Delayed Recall & Numeracy \\
\hline CLR & 0.000 & 0.000 & 0.000 \\
AR & 0.000 & 0.000 & 0.000 \\
J & 0.685 & 0.851 & 0.892 \\
\hline
\end{tabular}

Notes: $p$-values for the CLR and AR tests correspond to the null hypothesis of $H_{0}: \beta_{k}=0$, where $k$ represents the cognition indicator. The $\mathrm{J}$ test, on the other hand, tests the null of instrument exogeneity $H_{0}: E(Z u)=0$. Failure to reject the latter suggests that exogeneity conditions are generally satisfied. All tests are robust to heteroskedasticity and have been clustered by individual respondent.

Our instrumental variables model of the effects of cognition on civic en-

\footnotetext{
${ }^{17}$ These tests are readily available under the weakiv Stata command written by Finlay et al. (2013).
} 
gagement appears to be robust to different checks and specifications, even in the presence of a presumably weak instrument (height). These results favor the claim that smarter individuals will also behave as better and more participatory citizens, for which we turn to the next section.

\section{Conclusions}

Using data on the elder European population from the SHARE database, we are able to examine the relation between cognitive abilities (as measured by three different indicators) and the degree to which an individual engages in society (an index made up of voluntary and charity activities as well as of participation in religions and/or political organizations). Through the use of both height and the availability of books when the respondent was ten as instruments for cognitive abilities, we find evidence of a seemingly strong causal link from cognition to participation: the higher the cognitive state of an individual, the more likely it is that she will be involved in her community. In other words, smarter individuals do seem to behave as better Samaritans.

Although the sample is made up of older adults aged 50 and over from twelve European countries -and who may arguably have more time at hand for recreational activities than other age-groups- it would be interesting to assess if the effect found in the present study holds true for the adult population as a whole. Moreover, the inclusion of a greater diversity of indicators for both cognitive ability and pro-social behaviors could help verify -or challenge- the robustness of the results. Improvements are also at hand if different degrees of availability of civic activities by geographical area could be accounted for. To our knowledge, however, the present study constitutes the first serious attempt to scrutinize the relationship between cognition and civic engagement through a non-experimental approach.

The impact of these results is manifold. For economists and game theorists, it supports the ample plea to move beyond the standard theory of individual choice in the direction of more versatile theories of collective decision, able to provide a better account of the contextual reality of humankind. Werationality and team-preference theories constitute two current efforts that 
go in this direction. For policy makers, on the other hand, it is an appeal not to underestimate the importance of keeping a mentally active society even in advanced age, which will potentially result in better and more participatory citizens and thus in the construction of a stronger democracy. However, improving cognitive abilities is a lifelong endeavor, as it heavily relies on the available educational and personal development opportunities in a given society. Our findings are in line with those of Jones (2006), in that improving a population's cognition levels (e.g., through better nutrition, health and school systems, particularly in the poorest countries), will increase commitment toward society and thus pave the road for a more cooperative world. 


\section{References}

Abbott, R., White, L., Ross, G., Petrovich, H., Masaki, K., Snowdon, D. and Curb, J. (1998). Height as a marker of childhood development and late-life cognitive function: the Honolulu-Asia aging study, Pediatrics 102: 602609.

Anderson, T. and Rubin, H. (1949). Estimation of the parameters of a single equation in a complete system of stochastic equations, The Annals of Mathematical Statistics 20: 43-63.

Andreoni, J. (1990). Impure altruism and donations to public goods: a theory of warm-glow giving, The economic journal 100(401): 464-477.

Andrews, D., Moreira, M. and Stock, J. (2008). Efficient two-sided nonsimilar invariant tests in IV regression with weak instruments, Journal of Econometrics 146: 241-254.

Bacharach, M. (2006). Beyond individual choice, Princeton, NJ: Princeton University Press.

Bekkers, R. (2006). Traditional and health-related philanthropy: The role of resources and personality, Social Psychology Quarterly 69(4): 349-366.

Bekkers, R. and Wiepking, P. (2011). A literature review of empirical studies of philanthropy eight mechanisms that drive charitable giving, Nonprofit and Voluntary Sector Quarterly 40(5): 924-973.

Ben-Ner, A., Kong, F. and Putterman, L. (2004). Share and share alike? gender-pairing, personality, and cognitive ability as determinants of giving, Journal of Economic Psychology 25(5): 581-589.

Berkman, L. F., Glass, T., Brissette, I. and Seeman, T. E. (2000). From social integration to health: Durkheim in the new millennium, Social Science $\mathscr{6}$ Medicine 51(6): 843-857. 
Bernheim, B. D. and Rangel, A. (2005). Behavioral public economics: Welfare and policy analysis with non-standard decision-makers, Technical report, National Bureau of Economic Research.

Brañas-Garza, P., Guillen, P. and del Paso, R. L. (2008). Math skills and risk attitudes, Economics Letters 99(2): 332-336.

Brandstätter, H. and Güth, W. (2002). Personality in dictator and ultimatum games, Central European Journal of Operations Research 10(3): 191-215.

Brown, E. and Lankford, H. (1992). Gifts of money and gifts of time estimating the effects of tax prices and available time, Journal of Public Economics 47(3): 321-341.

Brunello, G., Weber, G. and Weiss, C. (2012). Books are forever: Early life conditions, education and lifetime income.

Camerer, C. F., Ho, T.-H. and Chong, J.-K. (2004). A cognitive hierarchy model of games, The Quarterly Journal of Economics 119(3): 861-898.

Case, A. and Paxson, C. (2008a). Height, Health and Cognitive Function at Older Ages, American Economic Review 98: 463-467.

Case, A. and Paxson, C. (2008b). Stature and status: Height, ability, and labor market outcomes, Journal of Political Economy 116: 499-532.

Charness, G. and Villeval, M.-C. (2009). Cooperation and competition in intergenerational experiments in the field and the laboratory, The American Economic Review 99(3): 956-978.

Christelis, D., Jappelli, T. and Padula, M. (2010). Cognitive abilities and portfolio choice, European Economic Review 54(1): 18-38.

Costa-Gomes, M., Crawford, V. P. and Broseta, B. (2001). Cognition and behavior in normal-form games: An experimental study, Econometrica 69(5): 1193-1235. 
Cunha, F. and Heckman, J. (2007). The technology of skill formation, American Economic Review 97(2): 31-47.

Cunha, F., Heckman, J. and Schennach, S. (2010). Estimating the technology of cognitive and noncognitive skill formation, Econometrica 78(3): 883931.

Denny, K. (2003). The effects of human capital on social capital: a crosscountry analysis.

Dewey, M. and Prince, M. (2005). Mental Health, Health, Ageing and Retirement in Europe - First Results from the Survey of Health, Ageing and Retirement in Europe MEA Eigenverlag: 108-117.

Everard, K. M., Lach, H. W., Fisher, E. B. and Baum, M. C. (2000). Relationship of activity and social support to the functional health of older adults, The Journals of Gerontology Series B: Psychological Sciences and Social Sciences 55(4): S208-S212.

Finlay, K., Magnusson, L. and Schaffer, M. (2013). weakiv: Weakinstrument-robust tests and confidence intervals for instrumental-variable (IV) estimation of linear, probit and tobit models.

URL: http://ideas.repec.org/c/boc/bocode/s457684.html

Fratiglioni, L., Paillard-Borg, S. and Winblad, B. (2004a). An active and socially integrated lifestyle in late life might protect against dementia, The Lancet Neurology 3(6): 343 - 353.

Fratiglioni, L., Paillard-Borg, S. and Winblad, B. (2004b). An active and socially integrated lifestyle in late life might protect against dementia, The Lancet Neurology 3(6): 343-353.

Frederick, S. (2005). Cognitive reflection and decision making, The Journal of Economic Perspectives 19(4): 25-42.

Gilbert, M. (1989). On social facts, New York: Routledge. 
Glei, D. A., Landau, D. A., Goldman, N., Chuang, Y.-L., Rodríguez, G. and Weinstein, M. (2005). Participating in social activities helps preserve cognitive function: an analysis of a longitudinal, population-based study of the elderly, International Journal of Epidemiology 34(4): 864-871.

Hansen, L. (1982). Large sample properties of generalized method of moments estimators, Econometrica 50(3): 1029-1054.

Hao, Y. (2008). Productive activities and psychological well-being among older adults, The Journals of Gerontology Series B: Psychological Sciences and Social Sciences 63(2): S64-S72.

Harsanyi, J. C. and Selten, R. (1988). A general theory of equilibrium selection in games, MIT Press Books $\mathbf{1}$.

Hauser, S. M. (2000). Education, ability, and civic engagement in the contemporary united states, Social Science Research 29(4): 556-582.

Heckman, J., Pinto, R. and Savelyev, P. (2012). Understanding the mechanisms through which an influential early childhood program boosted adult outcomes, Technical report, National Bureau of Economic Research.

Hillygus, D. S. (2005). The missing link: Exploring the relationship between higher education and political engagement, Political Behavior 27(1): 2547.

Hodgson, D. H. (1967). Consequences of utilitarianism, Oxford: Clarendon Press.

Hollis, M. (1998). Trust within reason, Cambridge: Cambridge University Press.

Hollis, M. and Sugden, R. (1993). Rationality in action, Mind 102: 1-35.

Hurley, S. L. (1989). Natural reasons, Oxford: Oxford University Press.

James, R. N. (2011). Charitable giving and cognitive ability, International Journal of Nonprofit and Voluntary Sector Marketing 16(1): 70-83. 
Jones, G., S. W. (2006). Intelligence, human capital, and economic growth: a bayesian averaging of classical estimates (BACE) approach, Journal of Economic Growth 11: 71-93.

Kahneman, D. and Tversky, A. (1981). The framing of decisions and the psychology of choice, Science 211: 453-458.

Kahneman, D. and Tversky, A. (1984). Choices, values, and frames., American psychologist 39(4): 341.

Kahneman, D. and Tversky, A. (1986). Rational choice and the framing of decisions, Journal of business pp. S251-S278.

Kleibergen, F. and Paap, R. (2006). Generalized reduced rank tests using the singular value decomposition, Journal of Econometrics 133: 97-126.

Maurer, J. (2010). Height, education and later life cognition in Latin America and the Caribbean, Economic and Human Biology 8(2): 168-176.

Moreira, M. (2003). A conditional likelihood ratio test for structural models, Econometrica 71: 1027-1048.

Nagel, R. (1995). Unraveling in guessing games: An experimental study, The American Economic Review 85(5): 1313-1326.

Oechssler, J., Roider, A. and Schmitz, P. W. (2009). Cognitive abilities and behavioral biases, Journal of Economic Behavior $\& 5$ Organization 72(1): 147-152.

Read, D., Loewenstein, G., Rabin, M., Keren, G. and Laibson, D. (2000). Choice bracketing, Elicitation of Preferences, Springer, pp. 171-202.

Regan, D. (1980). Utilitarianism and cooperation, Oxford: Clarendon Press.

Rousseau, J., Cranston, M. and Cranston, M. (1984). A Discourse on Inequality, Classics Series, Penguin Adult. 
Sabater-Grande, G. and Georgantzis, N. (2002). Accounting for risk aversion in repeated prisoners dilemma games: An experimental test, Journal of economic behavior $\&$ organization 48(1): 37-50.

Samuelson, L. (2005). Foundations of human sociality: A review essay, Journal of Economic Literature 43(2): 488-497.

Smerilli, A. (2012). We-thinking and vacillation between frames: filling a gap in Bacharachs theory, Theory and decision 73(4): 539-560.

Staiger, D. and Stock, J. (1997). Instrumental variables regression with weak instruments, Econometrica 65: 557-86.

Stock, J. H. and Yogo, M. (2005). Testing for weak instruments in linear IV regression. Chapter 5 in Identification and Inference in Econometric Models: Essays in Honor of Thomas J. Rothenberg, edited by DWK Andrews and JH Stock.

Sugden, R. (1993). Thinking as a team: Toward an explanation of nonselfish behavior, Social Philosophy and Policy 10: 69-89.

Sugden, R. (2000). Team preferences, Economics and Philosophy 16: 175204.

Sugden, R. (2003). The logic of team reasoning, Philosophical Explorations 16: $165-181$.

Wiepking, P. and Maas, I. (2009). Resources that make you generous: Effects of social and human resources on charitable giving, Social Forces 87(4): 1973-1995.

Wooldridge, J. (2001). Applications of Generalized Method Moments Estimation, Journal of Economic Perspectives 15(4): 87-100.

Wooldridge, J. (2002). Econometric Analysis of Cross Section and Panel Data, MIT Press. 
Zunzunegui, M. V., Alvarado, B. E., Del Ser, T. and Otero, A. (2003). Social networks, social integration, and social engagement determine cognitive decline in community-dwelling spanish older adults, The Journals of Gerontology Series B: Psychological Sciences and Social Sciences 58(2): S93S100. 